\title{
PRESENCIA TOLEDANA EN LAS YESERÍAS MUDÉJARES ARAGONESAS DEL SIGLO XVI
}

\author{
Pilar Navarro Echeverría
}

El siglo XVI en Zaragoza se caracteriza por un gran auge económico, que tiene su manifestación plástica en el amplio desarrollo que se produce en el mundo de las artes. Durante estos años se van introduciendo, poco a poco, todas las novedades del renacimiento que convive, en los primeros años del siglo, con las manifestaciones del gótico final y con la tradición mudéjar aragonesa.

Este contexto histórico es el que permite aventurar la hipótesis de trabajo que este artículo desarrolla: la aparición de temas y técnicas que resultan novedosas y ajenas a la tradición aragonesa en el campo de las yeserías mudéjares del siglo XVI, impulsada por la existencia de talleres procedentes de otras regiones españolas. Podemos encontrar numerosos maestros de obras mudéjares trabajando como mazoneros, fusteros, alfareros, azulejeros o aljeceros. Muchos de ellos llegaron a la capital aragonesa atraídos por el buen momento económico de la ciudad, llamados por mecenas nobles, comerciantes o la propia realeza para participar en la construción de casas, palacios, iglesias y conventos.

Desde que surgen las primeras manifestaciones del mudéjar en Aragón, la principal fuente de inspiración había sido el palacio musulmán de la Aljafería. En el caso de las yeserías, la reproducción de sus temas tanto geométricos como vegetales había sido una constante que sólo había variado con la llegada de las novedades procedentes de los lenguajes gótico y renacentista.

Sin embargo, en el siglo XVI nos encontramos con temas de clara procedencia islámica pero raros en la geografía aragonesa. Es el caso, por ejemplo, del púlpito de la llamada sala de la Limosna, en el claustro de la catedral de Huesca.

Este púlpito, junto a otros de la provincia de Huesca, ya había sido estudiado con anterioridad por Ricardo del $\mathrm{Arco}^{1}$, para quien podría haber

1. Ricardo Del. ARCo, Catálogo monumental de España: Huesca, Madrid, 1942, p. 410, fig. 483. 
sido realizado por el mismo artífice que hizo el púlpito del monasterio de Montearagón. Dos son las publicaciones en las que menciona este púlpito, desaparecido en la actualidad, pero que dicho autor parece haber visto. Lo nombra en un estudio que realiza sobre el monasterio de Montearagón ${ }^{2}$, donde nos informa que en la iglesia del convento "hacia 1520, el maestro de Santa Cruz hizo en aljez o yeso el púlpito, resabiado todavía de mudejarismo". Aparece también en el Catálogo de la Provincia de Huesca, donde lo describe con las mismas palabras que en la anterior publicación, pero añadiendo la fuente documental que permite conocer el nombre del maestro que lo realiza y la fecha aproximada de su ejecución ${ }^{3}$. Se trata de un dato procedente del Archivo Histórico Provincial de Huesca, protocolo de García Lafuente, que Arco cita como situado en el folio 82 y que en la reciente revisión realizada de la documentación de dicho notario, lo encontramos en el folio 96, dentro del documento de capitulación, que ocupa los folios 94 al 96 v. En esta capitulación, fechada en 1522, las monjas del convento de Casbas contratan una serie de obras con el maestro fustero Damián Aibar. Entre las cláusulas del contrato se pacta la realización de un púlpito de aljez similar al realizado en el monasterio de Montearagón por el maestro Santa Cruz (ver Apéndice documental). Es en este catálogo donde Arco nos sugiere que el púlpito de Huesca, el del monasterio de Casbas y el de Montearagón podrían haber sido realizados por este mismo autor.

Como ya hemos dicho con anterioridad, el púlpito de Montearagón no se conserva. Entre los restos de la iglesia existe una hornacina con huellas de haber tenido un antepecho que ha sido arrancado. Este podría haber sido el emplazamiento del púlpito que tratamos (fig.1). La escasa decoración todavía existente, es del siglo XVI. En la parte superior se aprecian los restos del timbre de un escudo episcopal. Si estos restos de decoración corresponden realmente al púlpito mencionado en la documentación, sólo dos de los abades que cita Ricardo del Arco en la monografía del monasterio ${ }^{4}$, por su cronología y sus cargos eclesiásticos, pudieron ser sus encargantes. Uno es don Alonso de Aragón, hijo natural de Fernando el Católico, que fue abad entre 1492 y 1520 y también arzobispo de Zaragoza desde 1478. Promovió obras artísticas en el monasterio de la envergadura del retablo ejecutado por Gil Morlanes el Viejo, conservado en la actualidad en la parroquieta de la catedral de Huesca. El otro es don Alonso de So Castro y Pinós, sobrino del anterior, también participó en la vida cultural del monasterio con la edición del breviario de Montearagón, para uso del abaciado y ocupó el cargo de obispo de Zaragoza.

2. Ricardo DEL ARCO, «El monasterio de Montearagón», Argensola, n59, 1963, pp. 3-49. Se reeditó debido a su interés y a la dificultad de consultar la anterior publicación de 1914.

3. Ricardo DEL ARCO, Catálogo monumental..., p. 180.

4. Ricardo DEL ARCO, «El monasterio...», pp. 10-11. 
Tanto don Alonso de Aragón como don Alonso de So de Castro, nos enlazan con la vida zaragozana. Residen en la ciudad, cerca de la corte y el rey. Es lógico pensar que para realizar las obras llevadas a cabo en Montearagón llamasen a artistas que estuviesen trabajando en la capital.

Carmen Gómez Urdáñez tiene documentados dos maestros de aljez, llamados Santa Cruz, que trabajan en Zaragoza en la primera mitad del siglo XVI ${ }^{5}$ y aunque de ellos no se especifica si son moros, el nombre de Santa Cruz es muy común entre los mudéjares convertidos. Estos maestros son Luis Santa Cruz y Francisco Santa Cruz. El primero procede de Toledo y está trabajando en Zaragoza desde 1514 en obras tan importantes como el monasterio de Santa Engracia, o la capilla de la Transfiguración de la cofradía de los obreros de villa y fusteros, en el convento de San Francisco. Tiene también documentados trabajos en la catedral de Barbastro (Huesca). El segundo presenta una cronología algo posterior. No está documentado hasta 1531, aunque podría haber estado trabajando en Huesca con anterioridad y ser esta la razón de su tardía aparición en la documentación zaragozana. La obra más importante en la que interviene es la mazonería de unas ventanas para el monasterio de Santa Engracia de Zaragoza.

Nuestro maestro de Santa Cruz bien podría ser Luis de Santa Cruz, procedente de Toledo. Son varías las razones que nos llevan a pensar en ello: en primer lugar es el que mejor se ciñe a la cronología de los púlpitos oscenses. Tal y como nos informa Carmen Gómez, este maestro aljecero trabaja en Zaragoza desde 1514. En 1517 firma la capitulación para la realización de la catedral de Barbastro, de modo que es posible que se encuentre todavía en activo en torno a la década de 1520. En segundo lugar, gracias a esta capitulación, sabemos que se encuentra trabajando en la zona y aunque no sea él quien finalmente lleve a cabo los trabajos de la catedral de Barbastro, sí pudo realizar otras obras en la provincia de Huesca. Por último, su procedencia toledana explicaría la existencia de determinados temas y técnicas ajenos a la tradición aragonesa.

Ya que los trabajos realizados por este aljecero en Zaragoza no se conservan, debido a la destrucción que sufrieron durante los sitios de la ciudad tanto el convento de Santa Engracia como el de San Francisco. Las posibles obras realizadas en la provincia de Huesca se convierten en ejemplos únicos de la influencia de las yeserías mudéjares toledanas en Aragón.

Comenzaremos por el púlpito de la sala de la Limosna, en el claustro de la catedral de Huesca, catalogado por Arco. Cuando éste lo fotografió se en-

5. Carmen Gómez URdÁÑzz, Arquitectura civil en Zaragoza en el siglo XVI, vol. II, p. 109 y nota 90. 
contraba completo (fig. 2) ${ }^{6}$. Hoy se halla muy deteriorado, en una zona de la catedral que se encuentra en estado de ruina.

Al igual que en el monasterio de Casbas, éste es un púlpito de refectorio. La sala para donde fue realizado era en un principio refectorio, y sólo más tarde, cuando perdió este uso, se adaptó para comedor de limosna, de ahí su nombre. En este comedor, durante el siglo XVI, se distribuía comida diariamente a unas setenta $u$ ochenta personas ${ }^{7}$. Durante las comidas era costumbre realizar lecturas religiosas, al igual que se hace en los monasterios, y para ello se utilizaba el púlpito.

No tiene ni tornavoz, del que probablemente no se le dotó nunca ya que no estaba destinado a un espacio grande, ni escalera de acceso. Está adosado a la pared y contaba con cuatro paneles decorados de los que sólo se conservan tres. En ellos se combinan motivos mudéjares con temas renacentistas. Es entre esta decoración donde encontramos que, tanto en el repertorio mudéjar como en el renacentista, existen temas que son extraños a la iconografía aragonesa tradicional.

Fue Ricardo del Arco, como hemos dicho con anterioridad, el que sugirió que este púlpito pudo haber sido realizado por el mismo taller al que se encargaron los desaparecidos de Casbas y Montearagón. La posibilidad de que fuera un artista de procedencia toledana, el maestro de Santa Cruz, el que trabajara en ellos nos ha llevado a descubrir el probable origen de los temas que lo decoran.

La búsqueda de influencias en las decoraciones toledanas de este siglo nos ha dado a conocer que no sólo alguno de los temas mudéjares oscenses son iguales que los de Toledo, sino que también lo son los renacentistas. Además, la técnica que se ha utilizado para realizarlos, que resulta igualmente novedosa en Aragón, coincide con la utilizada en la ciudad castellana. Como fuente de ejemplos toledanos hemos utilizado el estudio realizado por Balbina Martínez Caviró sobre los palacios y conventos mudéjares de la ciudad de Toledo ${ }^{8}$.

El primer tema que estudiamos (fig. 3), desarrolla una retícula de rombos enlazados. El interior de cada rombo está decorado con una flor de cuatro pétalos con círculo central, realizado a molde. En Toledo encontramos un

6. Algunas de las fotografías presentadas en este artículo proceden de las realizadas por Ricardo del Arco. Otras están tomadas en el año 1990, en ellas se aprecia su mal estado de conservación.

7. Antonio DURÁN GUDIOL, «Un informe del siglo XVI sobre el obispado de Huesca», Argensola, n' VIII, 1957 pp. 273-295.

8. Balbina Martínez Caviro, Mudéjar toledano. Palacios y conventos, Toledo, 1980. El estudio sólo se refiere a una parte de los edificios de la ciudad de Toledo por lo que podrían encontrarse todavía más semejanzas en los edificios y localidades no tratados en esta publicación. 
tema de gran semejanza. Se trata de la decoración de una ventana del patio de los Aljibes, en el monasterio de la Concepción Franciscana. Dicho convento sufrió, en los primeros años del siglo XVI, obras de acondicionamiento debidas a la instalación en sus dependencias de las monjas de la Concepción, que lo habían recibido como donación de la reina Isabel la Católica. Estas obras se encuentran documentadas en los libros de cuentas e inventarios de 1501 a $1510^{9}$. Entre ellas está el claustro bajo y el patio de los Aljibes donde se halla la mencionada ventana. El tema que decora sus laterales presenta rombos formando parte de una trama de lazos de cuatro combinados con estrellas de ocho puntas (fig. 4). La forma en que se entrelaza la retícula es la misma que en el motivo del púlpito, así como es igual la decoración interior a base de flores de cuatro pétalos con círculo central realizadas a molde. También en el claustro bajo se utilizan estos temas decorativos florales dentro de retículas geométricas de lazos mudéjares de cuatro, seis y ocho ${ }^{10}$.

El segundo panel está decorado a base de cuadrados flanqueados por alfardones, cuyo interior se decora con temas vegetales: una flor en el centro y haces de laurel en los hexágonos (fig. 5). Este mismo tema nos lo encontramos decorando uno de los vanos del claustro del monasterio de Santo Domingo el Real, en Toledo. Este monasterio se amplió a finales del siglo XV y las obras se continuaron en los primeros años del siglo siguiente tal y como documentan los libros de cuentas de 1507 y $1508^{11}$. El dintel de esta puerta está cubierto en su totalidad por cuadrados enmarcados por alfardones, en cuyo interior hay pequeños haces de laurel (fig. 6).

Por último, analizaremos el tema más raro de los tres. Se trata de una decoración de tipo vegetal insertada en un esquema de sebqa (fig. 7). No hemos encontrado ninguno igual en la publicación utilizada como referencia de la obra toledana, pero sí semejanzas que nos permiten relacionarlo con ella. El modo de distribuir los temas decorativos dentro de una retícula curvilínea, es una degeneración de temas procedentes del arte mudéjar toledano de los primeros siglos, que en el XVI es utilizado para articular los espacios decorativos, como en el caso de la puerta de la sala capitular del monasterio de Santo Domingo el Antiguo, que abre a claustro (fig. 8). En cuanto al tema que rellena esta retícula, no se ha localizado ninguno igual, pero sí de gran similitud, de nuevo en el monasterio de la Concepción Franciscana, en unas yeserías de comienzos del siglo XVI (fig. 9).

En lo que se refiere a la técnica son también numerosos los puntos en común entre las yeserías del púlpito de la catedral de Huesca y las toleda-

\footnotetext{
9. Ibiden, p. 72 .

10. Ibiden, p. 74 .

11. Ibidem, p. 376.
} 
nas. Frente a la técnica más difundida en Aragón de trabajo del yeso, consistente en la realización de un esquema geométrico previo, sobre el que luego se aplica el yeso, bien a mano, bien a molde y finalmente tallado para dejar la obra bien acabada, aparece el modo de trabajo toledano en el que se utilizan puntos como base para luego desarrollar mejor los temas geométricos. Tanto en el segundo panel de Huesca como en claustro de la Concepción Franciscana, en Toledo, se aprecian claramente estos puntos (figs. 5 y 10). En lo que se refiere a la técnica de la decoración vegetal, parece clara la utilización de moldes tal y como, afirma Balbina Martínez Caviró, se hacía tradicionalmente en las yeserías mudéjares toledanas para la realización de los centros de flores ${ }^{12}$. En la decoración vegetal de temática mudéjar, hay una peculiaridad toledana que se aprecia en el tercer panel de Huesca, la decoración de los motivos vegetales mediante incisiones triangulares.

Todas estas características, que se aproximan tanto a lo toledano, son las que nos llevan a elaborar la hipótesis de que el maestro de Santa Cruz citado en el documento de Casbas, coincide con el maestro de aljez documentado por Carmen Gómez Urdáñez, Luis Santa Cruz. Él o su taller bien pudieron haber trabajado en la catedral de Huesca.

Afortunadamente, no es el púlpito de la sala de la Limosna la única obra con características claramente toledanas que se conserva en Aragón. En la colegiata de Alquézar, a mitad de camino entre Huesca y Barbastro, dos de los lugares donde tenemos noticias del trabajo del toledano Luis Santa Cruz, existe una capilla cuyo ingreso está decorado con una rica yesería que combina los temas mudéjares con los renacentistas. Se trata de la capilla de San Fabián, situada en el claustro de la colegiata, a la izquierda de la puerta de ingreso de la iglesia. Antonio Durán Gudiol, en una de sus publicaciones sobre Alquézar, data la construcción de la iglesia entre 1515 y 1532 y se documenta una visita a las capillas del claustro en $1560^{13}$. La capilla es, por tanto, anterior a esta fecha. Por su vinculación a Toledo, y con ello al maestro Santa Cruz, se pudo haber realizado durante las obras de la fábrica de la iglesia, en torno a la década de 1520 .

Esta capilla está decorada con temas mudéjares en el intradós de su arco y en las enjutas que se combinan con temas renacentistas de candilieri en las pilastras que la flanquean (figs. 11 y 12). La decoración es a base de hojas de palma opuestas, aserradas, dispuestas dentro de un entramado de retícula vegetal a modo de paño de sebqa. El intradós del arco se decora con cardos, granadas colgantes y otros motivos vegetales. Algunos de estos temas los vemos también en la decoración de uno de los vanos del patio de los

12. Ibidem, p. 72 .

13. Antonio Durán Gudiol, Historia de Alquézar, Huesca, 1979, pp. 177-179. 
Aljibes del monasterio de la Concepción Franciscana (fig. 13). Se trata de un vano adintelado cuyos paneles laterales se decoran con un motivo muy similar al de las enjutas de la embocadura de la capilla de San Fabián. Hojas aserradas, simétricas y opuestas que forman una composición en retícula.

Como conclusión a la tesis planteada se puede decir que la movilidad de los artistas mudéjares es algo cotidiano. La presencia de maestros de obras mudéjares en Zaragoza y otros puntos de Aragón procedentes de distintas áreas de la Península queda reflejada, por ejemplo, en los trabajos de azulejeros sevillanos, que decoraron el muro de la "parroquieta" de la Seo de Zaragoza en el XIV. Asimismo, se ha documentado trabajando en la catedral de Huesca en 1522 Mahoma el Toledano, azulejero que trabaja junto a otros procedentes de Cadrete (Zaragoza). La influencia de la obra toledana en la catedral de Huesca, queda patente en la capilla del Sacramento, que se decora, en 1540, con azulejos de tipo toledano. Igualmente en otros puntos de Aragón, como en Utebo, vemos azulejería que repite temas toledanos ${ }^{14}$. Del mismo modo, también artistas mudéjares zaragozanos se trasladaban a trabajar en otros lugares, para realizar obras diversas como es el caso de Ali de Ariza, de la familia de aljeceros de Calatayud de los Domalich, llamado a trabajar en el desaparecido palacio del cardenal Mendoza, en Guadalajara ${ }^{15}$, o los hijos de Mofferiz, maestro de obras de la Aljafería, contratados para trabajar en la Alhambra de Granada en $1492^{16}$. Los talleres se trasladan a los lugares donde hay más ofertas de trabajo lo que explicaría la presencia del aljecero toledano Luis de Santa Cruz en Zaragoza.

Cronológicamente dicho maestro se ajusta también a la tesis planteada. Está documentada su presencia en Zaragoza a partir de 1514 y en la provincia de Huesca desde 1517 y durante la década de 1520. Estas fechas le habrían permitido participar o al menos conocer las obras toledanas que aquí hemos tomado como referencia, ya que todas ellas están documentadas como realizadas con anterioridad a 1514. El convento de la Concepción Franciscana se reforma entre 1501 y 1510, el claustro y la sala capitular del convento de Santo Domingo de Silos o el Antiguo, datados a finales del siglo XV y principios del XVI, y el convento de Santo Domingo el Real, cuyas obras de ampliación están documentadas en los años 1507 y 1508.

14. M" Isabel Alvaro Zamora, "Técnicas e innovaciones en la cerámica aragonesa», Actas del curso Las artes en Aragón durante el reinado de Fernando el Católico, Institución Fernado el Católico, Zaragoza, 1993, pp. 203, 207 y 208.

15. Francisco Javier GARCia MARCO, «Un capítulo para la historia social del yeso», Actas del V Simposio Internacional de Mudejarismo, Teruel, 1991, p. 354.

16. Antonio DE LA TORRE y EL CERRO, «Moros zaragozanos en obras de la Aljafería y de la Alhambra», Anuario del cuerpo facultativo de archiveros, bibliotecarios y arguleólogos, Madrid, 1935, pp. 249-255. 
El estudio comparativo de los temas conservados en Aragón con los existentes en Toledo, nos ha permitido encontrar paralelismos de gran parecido de los que podemos deducir su procedencia de una manera lógica. La coincidencia de algunos temas, la semejanza de otros y la aparición de formas de trabajar el yeso, novedosas en Aragón pero tradicionales entre los aljeceros mudéjares toledanos son también prueba de este intercambio.

\section{APÉNDICE DOCUMENTAL}

1522 julio 25

Huesca

Capitulación y concordia entre la abadesa, prioras y religiosas del monasterio de Casbas y Damián Aibar, maestro fustero, para unas obras en el refectorio del monasterio. En una de las cláusulas del contrato se pacta la realización de un púlpito de aljez similar al realizado en el monasterio de Montearagón por el maestro Santa Cruz.

"...Ite[m.] es pacto y condicion y se obliga dicho maestro de azer una trona pa[ra] leer en dicho refectorio, de aljez, en el lugar q[ue] sera dispuesto q[ue] mas combenga, por las señoras abadesa y religiosas, de manera q[ue] este bien, la cual ha de ser obrada por maestro Santa cruz o otro q[ue] sea buen ofiÇial como la q[ue] esta en monte aragon..."

A.H.P.H. Not. García Lafuente, 1522, ff. 94-96. 153 y 180 .

Ricardo del ArCo, Catálogo Monumental de España. Huesca, Madrid, 1942, pp. 

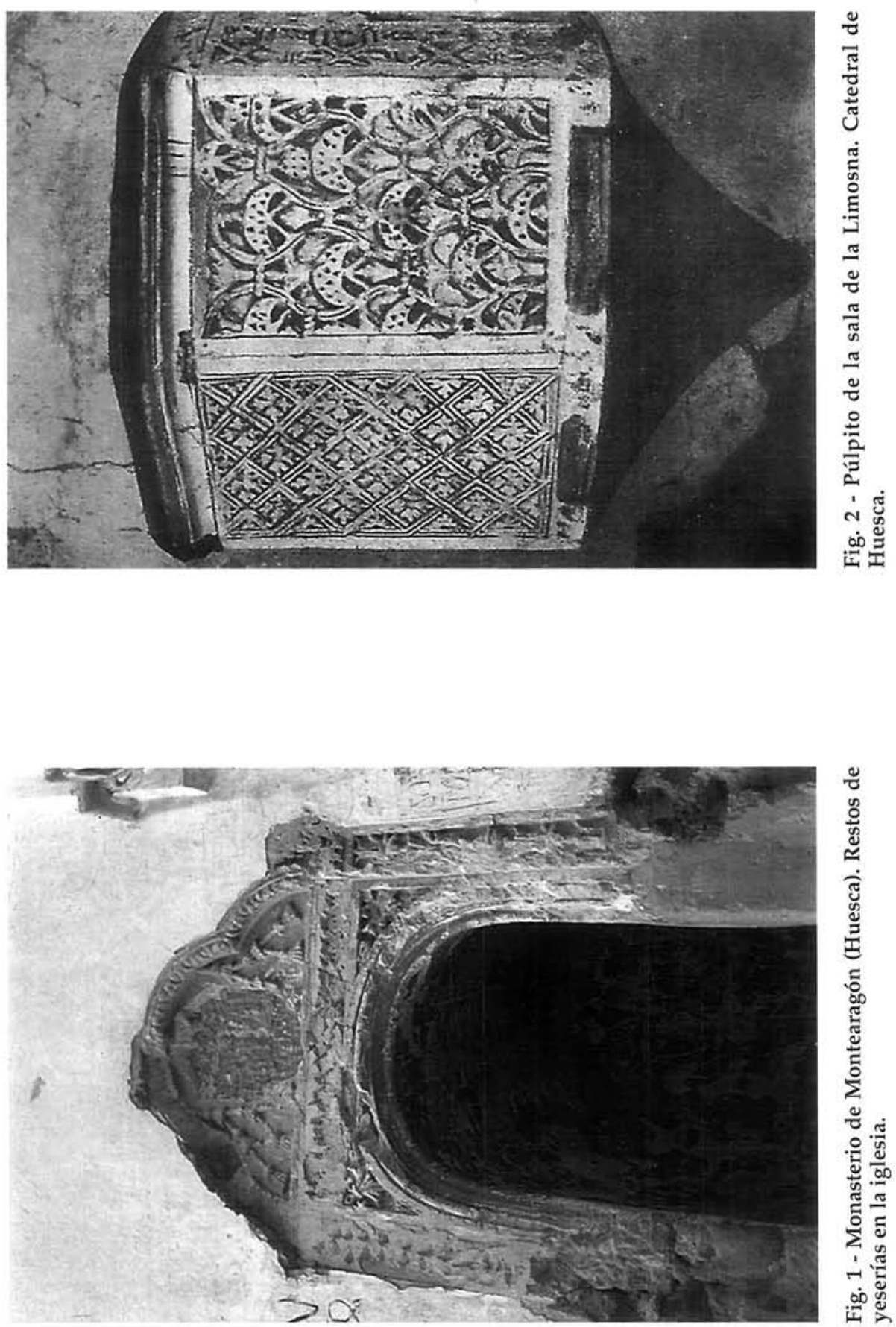


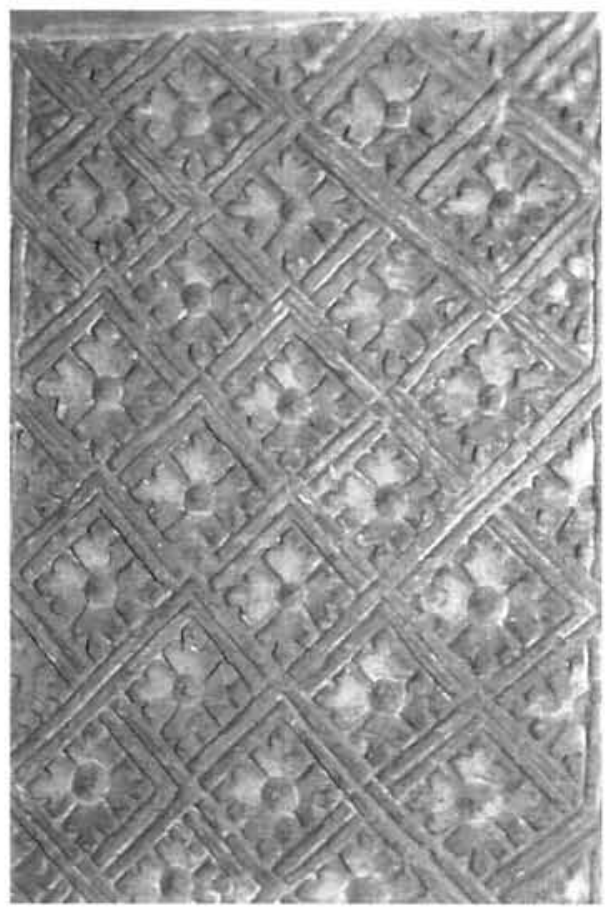

Fig. 3 - Detalle de uno de los paneles del púlpito de la sala de la Limosna. Catedral de Huesca.

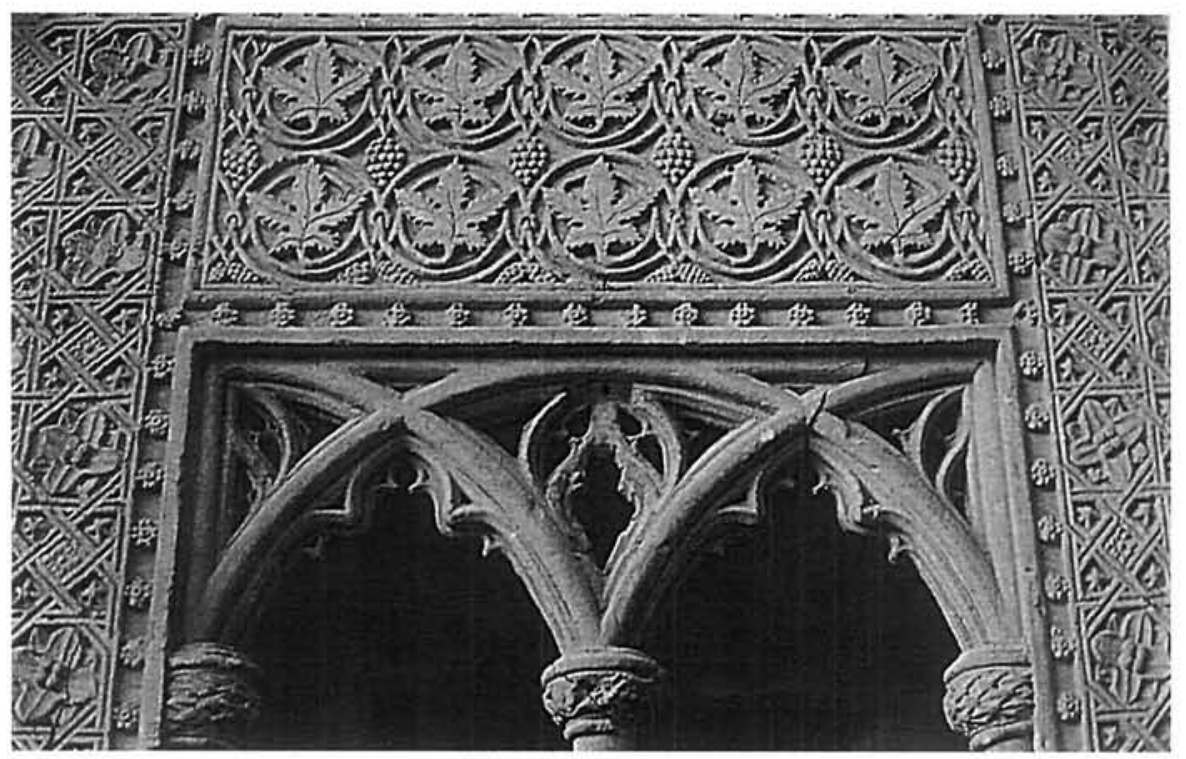

Fig. 4 - Monasterio de la Concepción Franciscana (Toledo). Vano del patio de los Aljibes. 


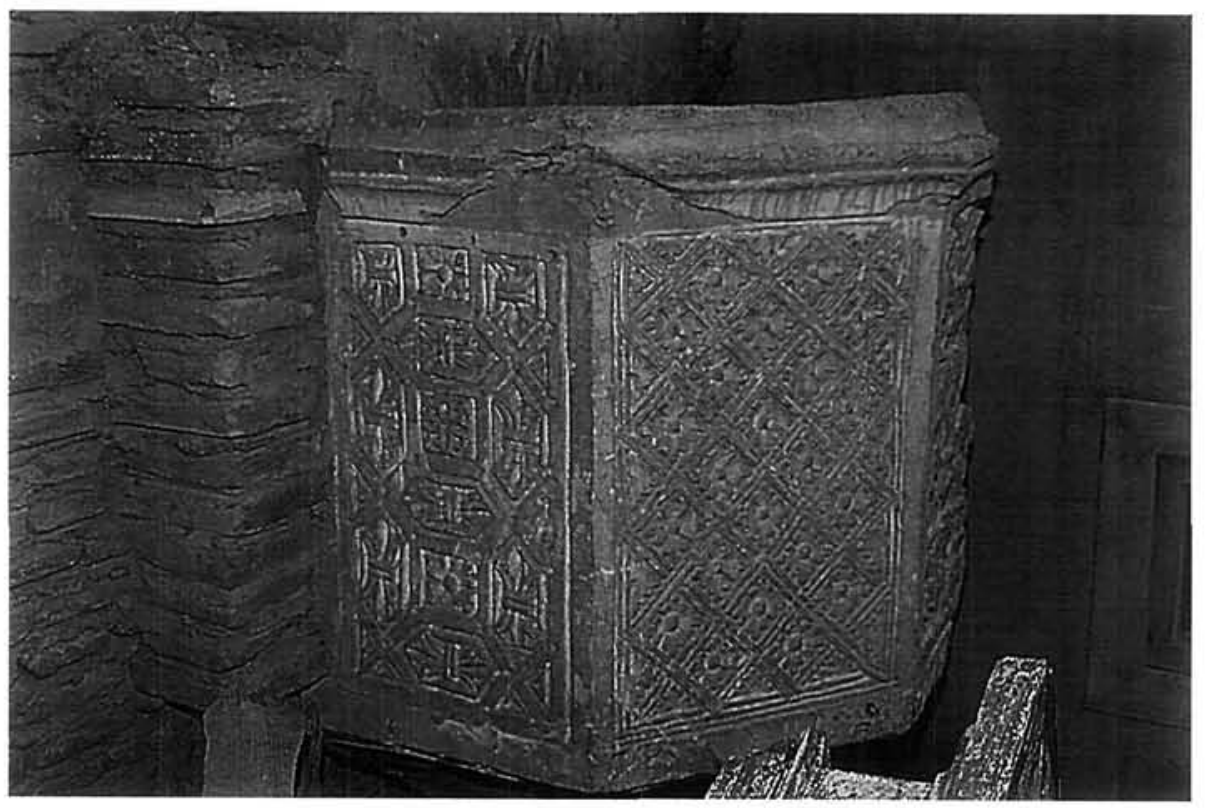

Fig. 5 - Panel izquierdo del púlpito de la sala de la Limosna. Catedral de Huesca.

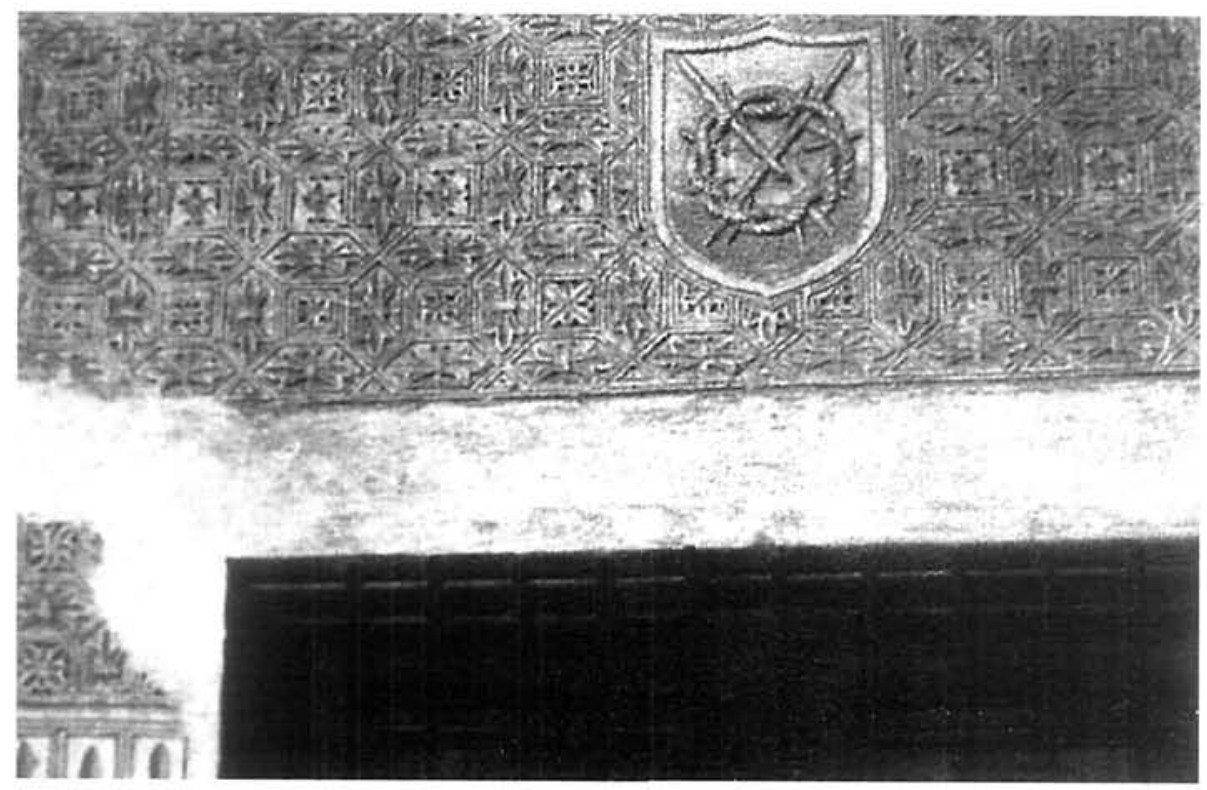

Fig. 6 - Claustro de Santo Domingo el Real (Toledo). Vano. 


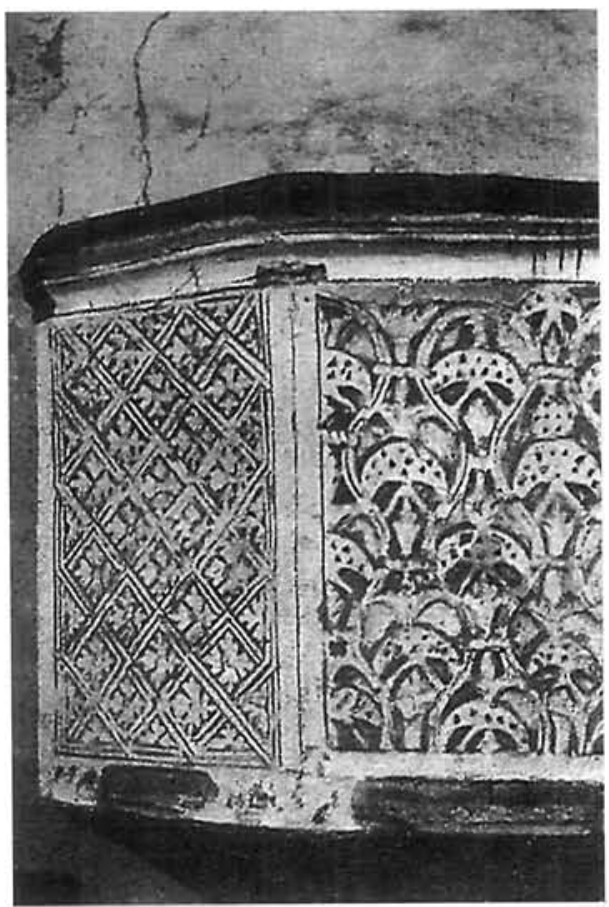

Fig. 7 - Panel del púlpito de la sala de la

Limosna. Catedral de Huesca.

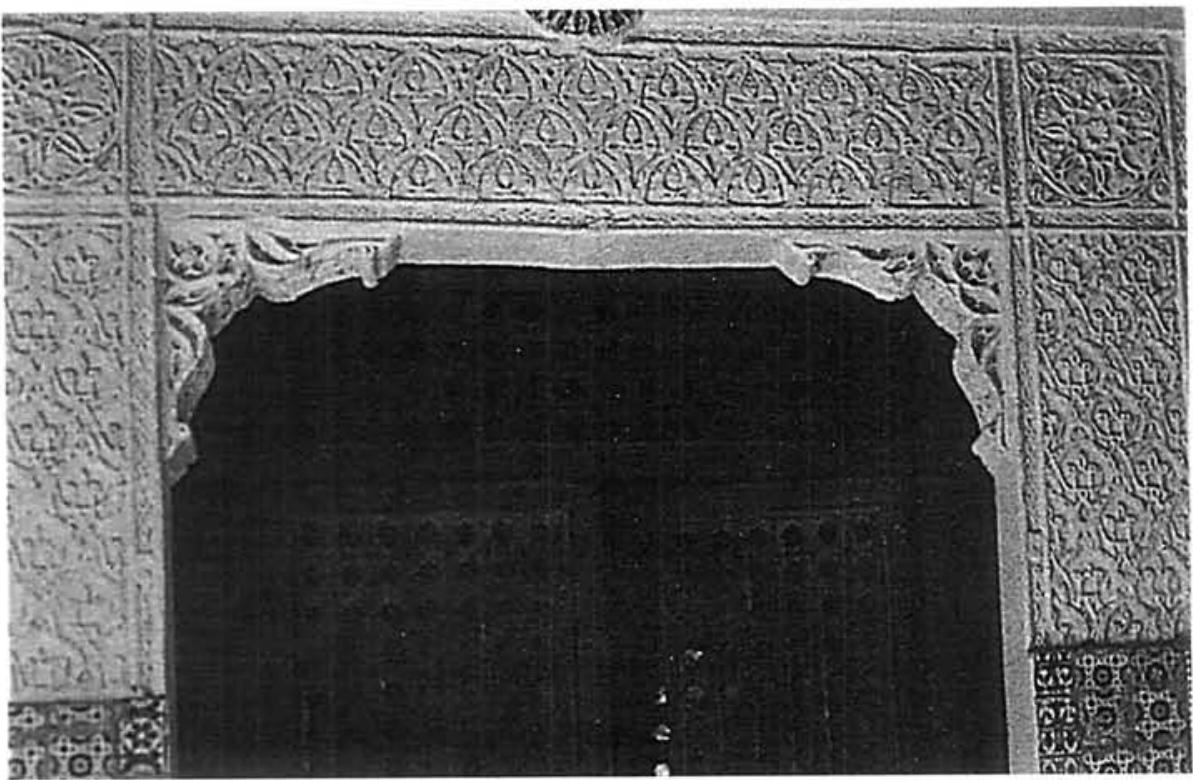

Fig. 8 - Sala capitular del monasterio de Santo Domingo el Antiguo (Toledo). Puerta. 

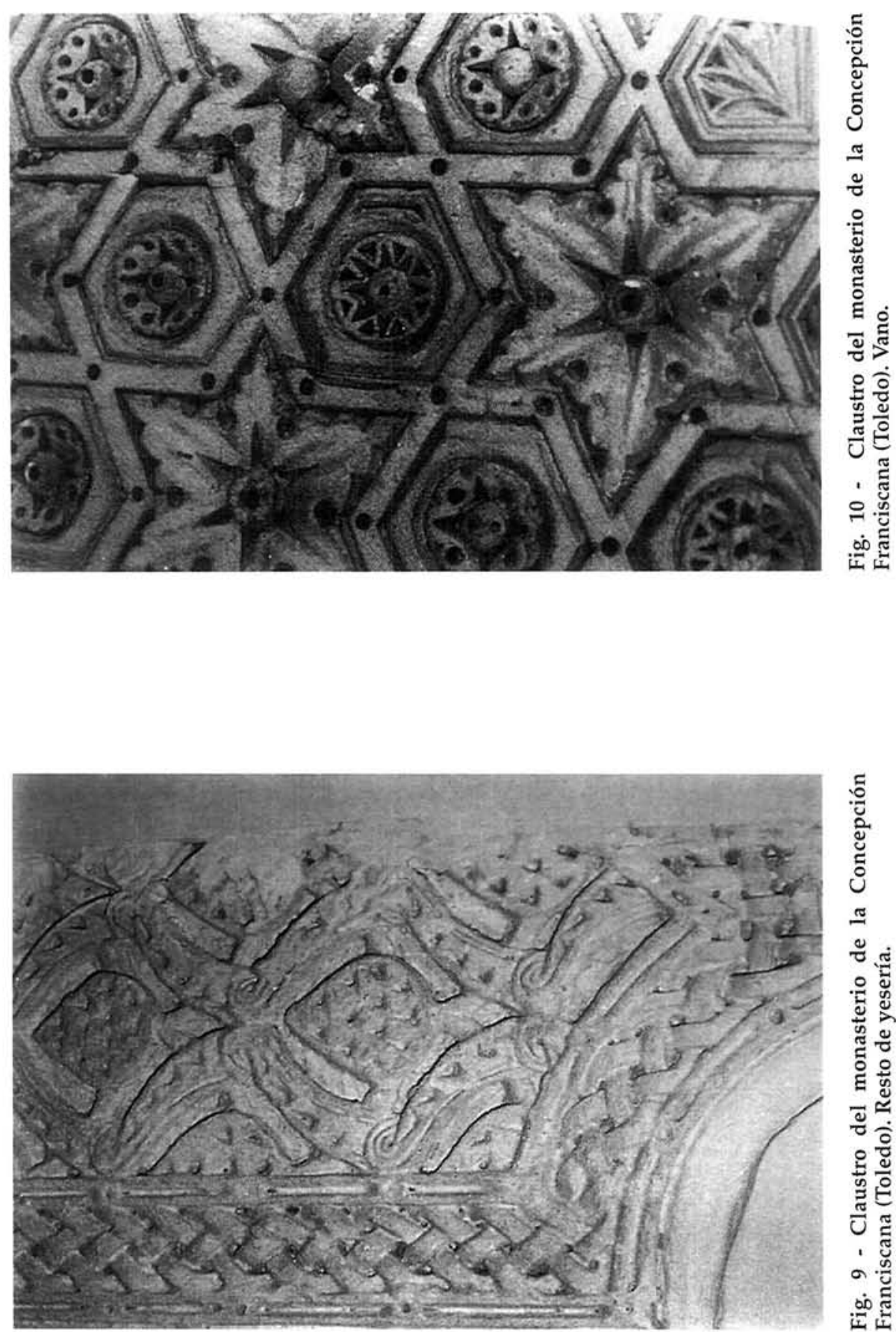


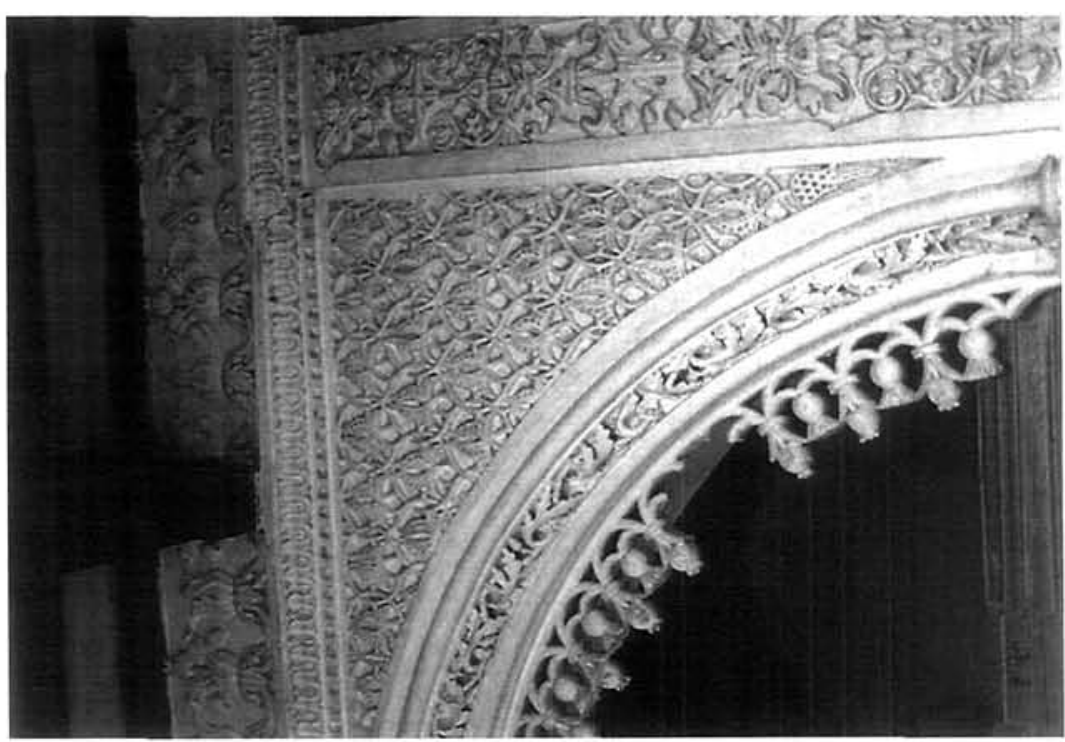

公占

ซั ซั

을

를

政

है 羟

क็ ญ्

तू ह

ฐ ํㅝㅇ

뜸

ํํㅇ

U요

픈

ชัँ

ํ. 듀

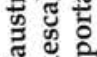

บ로도

, 过。

ㄱำ

ob

诖卷岲

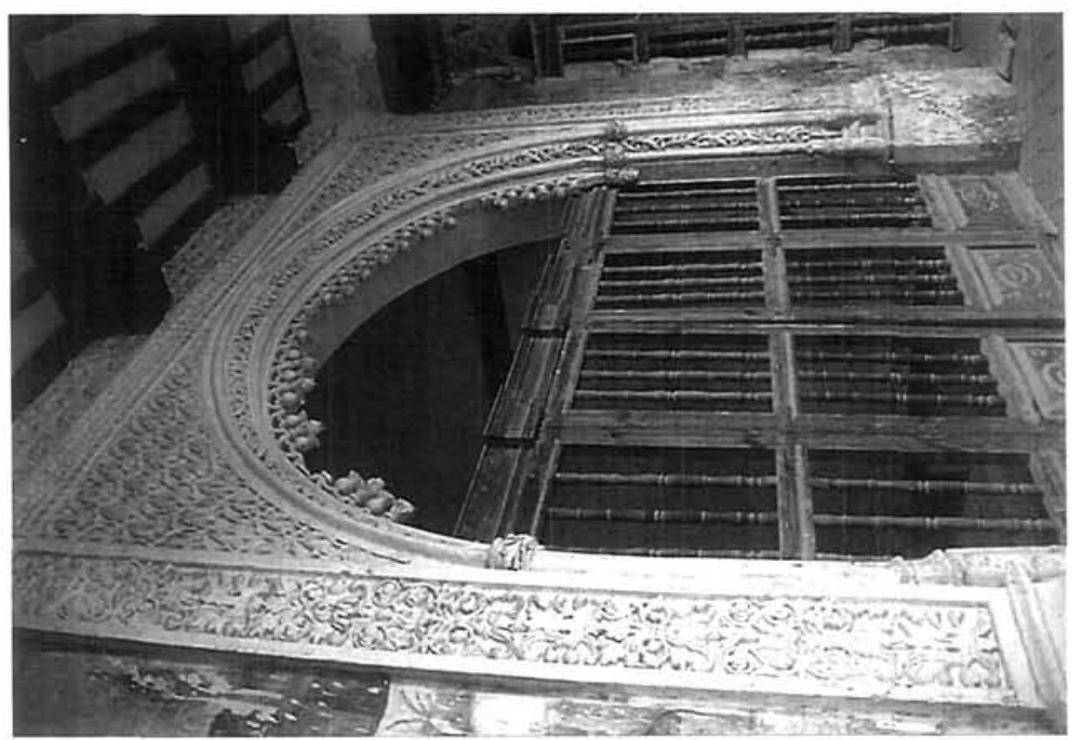

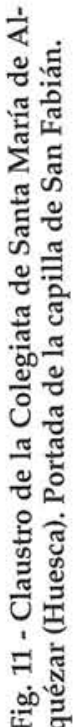




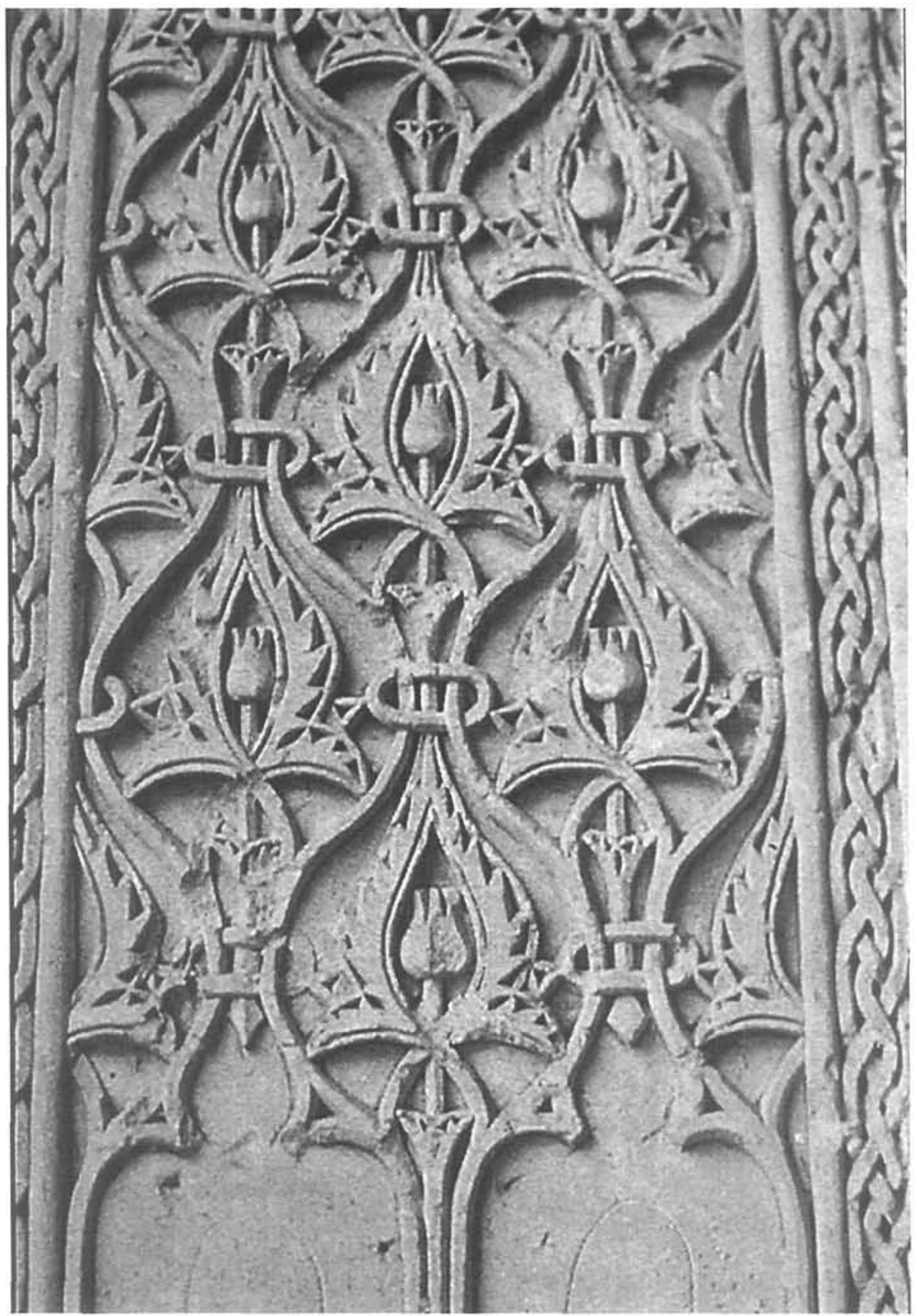

Fig. 13 Monasterio de la Concepción Franciscana (Toledo). Vano del patio de los Aljibes. 